how not to make those connections, but the most important book that Bruer could give us will tell a different story. This book ends where his work, and the emerging field of developmental cognitive neuroscience, begin.

Elizabeth Spelke is in the Department of Brain and Cognitive Sciences, Massachusetts Institute of Technology, Cambridge, Massachusetts 02139, USA.

\section{Oiling the wheels of controversy}

\author{
The Deep Hot Biosphere \\ by Thomas Gold \\ Springer: 1999. 235 pp. \$27, £19
}

\section{R. John Parkes}

Modern society relies heavily on petroleum for energy, and life would be very different without it. The term 'fossil fuel' effectively informs us that the origin of oil is from the bodies of dead plants and animals, altered initially by microbial decay, and then 'cooked' under pressure and at relatively high temperatures during burial to several kilometres' depth.

We have 'harvested' this deep resource extremely rapidly, but we also realize that we will eventually run out of this precious commodity. But what if someone told you that this was all wrong and that the hydrocarbons that make up petroleum are constantly refilling reservoirs. Interested? Well, you should read this book. Thomas Gold postulates that oil and gas are of primordial, abiological origin, part of the solid material that accreted to form the planet some 4.5 billion years ago. As the planet subsequently heated up (through radioactive decay and gravitational compression and sorting), only partial melting occurred, producing the different layers of the Earth (crust, mantle and core), and enabling the primordial hydrocarbons and/or their precursors to survive. Gold suggests that these are concentrated at great depths - 100 to 300 kilometres - and are constantly moving towards the surface as fluids and gases via conduits within rocks and collecting in oil reservoirs.

As you might expect, this is a very controversial theory, with both passionate supporters and objectors. It is also in conflict with the basis for current petroleum exploration. It was first presented in the late 1970s, when it was considered that oil reserves would last for only another 15 years, prompting an oil crisis. Not surprisingly, as the theory promised continued supplies of hydrocarbons, it received considerable attention from petroleum entrepreneurs, but it was, and still is, broadly rejected by scientists. An additional aspect of the theory is that oil and gas should not be restricted to sedimentary deposits, as dictated by the biogenic theory of oil formation, but should be widespread in all rock types, including rocks formed from magma.

This would greatly widen the areas for oil exploration, and in 1986 Gold persuaded the Swedish government to drill 6.7 kilometres into granite to prove his theory. The results of this experiment are reported in detail, but unfortunately, little of this has been published in the scientific literature, which is essential to validate a theory of such major significance. Gold explains, with some frustration, that this is due to scientists' unwillingness to be open to this new theory, leading them to reject his results. If commercial quantities of oil and gas had been produced, Gold's theory would have been willingly accepted; however, only limited amounts of oil were produced. Gold claims that this is sufficient to prove his theory, but scepticism prevails.

One major problem is that petroleum contains 'molecular fossils', clear fingerprints of a biological origin, and thus cannot be of primordial, abiological origin. Gold, however, addresses this problem by hypothesizing that, as the hydrocarbons migrate upwards, they are intercepted by a deep subsurface bacterial biosphere, which uses some of the hydrocarbons as an energy source. Hence, it is these bacteria that provide the biological fingerprint to oil and not organisms that originally lived at the surface and gained their energy from sunlight via photosynthesis.

Gold suggests that this deep biosphere may extend down to 10 kilometres, which would mean high temperatures (between 150 and $300{ }^{\circ} \mathrm{C}$ ), and hence he has termed it "the deep, hot biosphere". The current temperature maximum for bacterial life is $113^{\circ} \mathrm{C}$; hence, bacteria living at even higher temperatures would have to exist to occupy this zone, and $300{ }^{\circ} \mathrm{C}$ seems improbably high. Pressures at this depth would also become limiting. In addition, hydrocarbons are relatively resistant to bacterial degradation, especially under the anaerobic conditions that must prevail in the deep subsurface. Therefore, it would be very difficult for bacteria to thrive under the conditions outlined by Gold.

Although many of the molecular fossils in petroleum could be explained by an origin from subsurface bacteria, some are clear indicators of surface photosynthetic organisms (for example, porphyrins and dinosteranes) and hence of a biological origin for the oil. Another problem is that petroleum is made up of isotopically light carbon, which again is indicative of a biological origin. Not necessarily so, says Gold, because he suggests that, during migration to the surface, isotopic fractionation of hydrocarbons containing isotopically heavy carbon would also result in isotopically light hydrocarbons being more abundant in oil reservoirs. He also states that some commercial methane sources are much lighter isotopically than can be explained by cell debris from plant photosynthesis, but this ignores the fact that methane-forming bacteria produce an extra isotope fractionation. Gold's deep-Earth gas theory, which he extends in this book to include black coal and diamond formation, the concentration of metals and involvement in earthquakes, is so radical that there are many inconsistencies and contradictions with empirical observations. The justification for these extensions may in places prove far from satisfying and sometimes also too anecdotal. Nevertheless, the book makes interesting reading, as Gold presents his evidence skilfully. You may not agree with him, but you have to appreciate his fresh and comprehensive approach to these major areas of Earth science.

At least one area Gold discusses in his book is starting to be substantiated, but there is no evidence that this is being fed by very deep primordial hydrocarbons. Surprisingly large bacterial populations have been found at considerable depths (up to a few kilometres) in a range of different subsurface environments, including terrestrial aquifers, granites and basalts, Cretaceous shales, marine sediments and the rocks beneath. There are even some locations where bacterial activity and populations increase in deeper zones and where geospheric processes may be involved in fuelling a bacterial biosphere to much greater depths than we had previously thought possible. Unfortunately, these are not fully reviewed in the book. The magnitude of this biosphere may also be huge, as Gold predicted. A startling example of this is the discovery that some North Sea oil reservoirs produce 3-16 kilograms of high-temperature bacteria along with the production fluid each day. In his book, Gold considers the implications of subsurface life for the origin of life on Earth and its subsequent evolution, and finally the possibility of life on other planets.

The book is clearly one man's view of major processes in the Earth sciences, and demonstrates that scientific debate is alive and well. Science is not just about facts and data, but is hypothesis-led and thrives on controversy - and few people are more controversial than Thomas Gold.

R. John Parkes is in the Department of Earth Sciences, University of Bristol,

Wills Memorial Building, Queens Road, Bristol BS8 IRJ, UK.

\section{More specialized extremes \\ Enigmatic Microorganisms and Life in Extreme Environments \\ edited by Joseph Seckbach \\ Kluwer Academic, £210, \$360}

